\title{
Serum IL-6, IL-8 and CRP as Markers for Prediction of Bacteremia by Gram Negative Rods in Febrile Cancer Patients and in Irradiated Rats
} Hala A Farrag ${ }^{1 *}$, Mohamed M Aboulwafa ${ }^{2}$, Khaled M Aboshanab² and Amira A Abdelbaset ${ }^{1}$

${ }^{1}$ Department of Drug Radiation Research, National Center for Radiation Research and Technology (NCRRT), Atomic Energy Authority, Cairo, Egypt

${ }^{2}$ Department of Microbiology and Immunology, Faculty of Pharmacy, Ain Shams University, Organization of African Unity St., P.O. Box: 11566, Abbassia, Cairo, Egypt

\begin{abstract}
In this study, serum inflammatory mediator's levels (IL-6 and IL-8) at fever onset to predict gram negative bacteremia in cancer patients have been determined. Also, the effect of gamma irradiation on IL- 6 serum levels has been investigated using animal model at dose level $24.4 \mathrm{~Gy}$. Seventy feverish in-patients were enrolled in the study. Blood samples were collected at onset of fever for assay of IL-6, IL-8, CRP, C3 and total leukocytic count. IL-6 and IL-8 serum levels were higher in patients with gram negative bacteremia than in those with non-microbial fever. For patients with gram negative bacteremia and those without there was significant difference in IL-6 and IL- 8 serum levels ( $P=0.0001$ and $P=0.0059$ respectively). While, $C R P$ and $C 3$ serum levels showed non-significant differences. Using (ROC), IL-6 was potentially useful with Sp, NPV of $100 \%$ and $398.6 \mathrm{pg} / \mathrm{ml}$ cut-off value and AUC of 1.000 compared to Sp $77.8 \%$, NPV $60 \%$ and AUC of 0.844 for CRP. On the other hand, IL-8 values didn't show overlapping in the groups. In the animal model, (ROC) for IL-6 serum concentration in bacteremia groups (due to Pseudomonas aeruginosa and Klebsiella pneumoniae) with exposure to gamma radiation and bacteremia groups without exposure to gamma radiation showed a cut-off value of $25740 \mathrm{pg} / \mathrm{ml}$ with $58.3 \% \mathrm{Sn}$, NPV $64.3 \%$. These results showed the potential usefulness of IL- 6 and IL- 8 as early predictors of gram-negative bacteremia than commonly used markers such as CRP and C3. Also, usefulness of serum IL-6 as marker discriminating between different fever episodes in cancer patients under radiotherapy.
\end{abstract}

Keywords: Gram negative rods; Bacteremia; C-Reactive protein; Interleukin-6; Interleukin-8; Cancer patients

\section{Introduction}

Bloodstream infection (BSI) continues to be a life-threatening condition. The bloodstream was the second most frequent infection site, representing $20 \%$ of all infections [1]. People in good health with strong immune systems rarely develop bacteremia. However, when bacteria are introduced directly into the circulatory system, especially in a person who is ill or undergoing aggressive medical treatment, the immune system may not be able to cope with the invasion and symptoms of bacteremia may develop. Symptoms of bacteremia may include: fever over $101^{\circ} \mathrm{F}\left(38.3^{\circ} \mathrm{C}\right)$, chills, malaise, abdominal nausea, vomiting, diarrhea, anxiety, shortness of breath and confusion. Conditions which increase the chances of developing bacteremia include: immune suppression, either due to HIV infection or drug therapy, antibiotic therapy which changes the balance of bacterial types in the body, prolonged or severe illness, alcoholism or other drug abuse, malnutrition, diseases or drug therapy that cause ulcers in the intestines, e.g., chemotherapy for cancer [2]. Prompt identification of early bacterial infection in fever is very important, since appropriate etiological treatment and avoidance of unnecessary antimicrobial therapy could not only reduce the morbidity, mortality and costs to patients, but also can reduce the emergence of antibiotic-resistant bacteria. Infections are still the major cause of treatment-related morbidity and mortality in cancer patients. The malignant disease and the intensive chemotherapy may cause an impaired host defense to infection, key factors are the intensity and duration of neutropenia, but a decreased function of granulocytes and disturbances of natural barriers may substantially add to the risk of serious infections [3]. Neutropenic cancer patients with bacteremia, in particular those with gram-negative bacteremia, appear to have a relatively high risk of complications and lethal outcome which is clearly higher than the risk of adverse outcomes associated with unexplained fever. The traditional diagnostic tools, such as C-reactive protein (CRP) and leukocyte count, are not specific enough for differentiating bacterial infections from viral infections and systemic inflammation [4]. Microbiologic culture requires at least $24 \mathrm{~h}$ to $48 \mathrm{~h}$, and negative cultures do not exclude the presence of infection [5]. Moreover, only 5\% to $10 \%$ of blood cultures performed in hospitals show microorganisms [6]. Gram-negative bacteria play an important role in bloodstream infections about $30 \%$ of cases in the ICU are caused by one or another species of Klebsiella, E. coli, Enterobacter species, and P. aeruginosa [7]. A variety of laboratory markers of systemic inflammation, such as interleukin- 6 (IL-6), interleukin- 8 (IL-8), and C-reactive protein (CRP) have been used to identify patients with infection. Of these markers, increased blood levels of IL- 6 and IL- 8 denote activation of monocytes/macrophages and both cytokines induce CRP synthesis in the liver [8]. This makes IL-6 an interesting molecule to evaluate in the early phase of infection and sepsis $[9,10]$. In neutropenic patients, enhanced IL-8 production has been demonstrated in predicting bacteremia [11]. Recognition of bacteria by complement components is likely to induce the activation complement pathways leading to the formation of a C3 convertase and the generation of complement activation products triggering diverse biological activities, such as microbial opsonization, phagocyte recruitment and inflammation, resulting in the elimination of pathogenic microorganisms $[12,13]$. The predominant gram-negative bacteria, $P$. aeruginosa and $K$. pneumoniae were isolated from blood of cancer patients under radiotherapy [14-17]. So, there is an obvious

*Corresponding authors: Hala A. Farrag, Department of Drug Radiation Research National Center for Radiation Research and Technology (NCRRT), Atomic Energy Authority, Cairo, Egypt, Tel: 201001573826; E-mail: hala_farrag_24@hotmail.com

Received April 26, 2016; Accepted July 20, 2017; Published July 24, 2017

Citation: Farrag HA, Aboulwafa MM, Aboshanab KM, Abdelbaset AA (2017) Serum IL-6, IL-8 and CRP as Markers for Prediction of Bacteremia by Gram Negative Rods in Febrile Cancer Patients and in Irradiated Rats. J Med Microb Diagn 6: 258 doi:10.4172/2161-0703.1000258

Copyright: ( 2017 Farrag HA, et al. This is an open-access article distributed unde the terms of the Creative Commons Attribution License, which permits unrestricted use, distribution, and reproduction in any medium, provided the original author and source are credited. 
Citation: Farrag HA, Aboulwafa MM, Aboshanab KM, Abdelbaset AA (2017) Serum IL-6, IL-8 and CRP as Markers for Prediction of Bacteremia by Gram Negative Rods in Febrile Cancer Patients and in Irradiated Rats. J Med Microb Diagn 6: 258. doi:10.4172/2161-0703.1000258

need for more specific biomarkers of bacterial infections in febrile cancer patients. The detection of CRP, IL- 6 and IL- 8 may be a better combination to identify early bacterial infection in febrile cancer patients. We, therefore, undertook this study to compare the diagnostic properties and assess the optimum cut-off values of these markers to detect gram negative bacteremia early in febrile cancer patients.

\section{Materials and Methods}

\section{Patients and samples}

A total of 70 cancer in-patients with fever onset admitted to public hospitals, private hospitals and Nasser Institute hospital, Cairo, Egypt were included in this study. Data on variables that could affect the results were recorded including age, gender, malignancies (diagnosed as Acute Myeloid Leukemia and solid tumors). Patients on prior treatment with drugs and antibiotics were excluded from the study. Venous blood samples were drawn by medical staff.

\section{Bacterial strains}

For bacterial cultures, routinely more than one blood culture bottle (BACTEC Peds Plus ${ }^{\mathrm{Tn}} / \mathrm{F}$, Becton Dickinson, Europe, France) for each patient were obtained. By using standard laboratory methods, contaminated blood culture or cultures positive for microbial growth other than gram negative bacilli were excluded from the study. In case of positive blood samples and after incubation 2 days to 7 days at $37^{\circ} \mathrm{C}$, cultivation was carried out on blood agar plates and MacConkey's agar plates (England) for isolation of gram negative bacilli only. Identification of isolated organisms from blood specimens was done by API 20E (BioMérieux, France).

\section{Blood sampling and assays}

Blood samples mixed with $\mathrm{K}_{2}$ EDTA containing vacutainer tubes (Becton, Dickinson Company, USA) were centrifuged immediately and plasma samples were used for total leukocytic count analysis. WBCs count was performed on $200 \mu \mathrm{l}$ plasma and determined by Beckman/Coulter, (USA) CBC-5 semi-automated located at Nasser Institute Hospital, Cairo, Egypt. While, blood samples vacutainer tubes containing thrombin were centrifuged immediately and sera were frozen at $-20^{\circ} \mathrm{C}$ until measurements and assay of CRP, IL-6, IL-8 and C3 (Instructions of the manufacturers were strictly followed). To determine normal levels of measured parameters, under the same conditions, serum samples were obtained from healthy volunteers. C-reactive protein (CRP) serum level was achieved by CRP-turbilatex through the turbiquick reader (Vital Diagnostics, Italy). IL-6 and IL-8 serum levels were measured by commercially available Enzyme Linked Immunosorbent Assay (ELISA) kit with a detection limit of 3 $\mathrm{pg} / \mathrm{ml}$ and $25 \mathrm{pg} / \mathrm{ml}$ respectively and the intensity of colored products was measured spectrophotometrically at $450 \mathrm{~nm}$. Serum IL-6 was measured by RayBio Human IL-6 ELISA kit (Raybiotech, Inc, USA). While, IL-8 serum levels were measured using (Diaclone SAS, France). Complement $\mathrm{C} 3$ activity was determined in serum samples using (radial immunodiffusion plate) DIFFU-PLATE (Biocientifica SA, Argentina).

\section{Irradiation source}

Cesium 137 (137 Cs) gamma cell 40 source product of Canada Co. Ltd. Canada, Located at National Center for Radiation Research and Technology, Nasr City, Cairo, Egypt. The dose rate at the time of experiments was $0.008 \mathrm{~Gy} / \mathrm{sec}$. An in vitro total single dose of 24.41 Gy/one fraction, used for radiotherapy of some cancer patients, was calculated according to the linear quadratic (LQ) formula described by Barton in 1995 [18], which is biologically equivalent to $70 \mathrm{~Gy} / 35$ fractions. All the microbiological tests were performed, twice for each isolate, one before irradiation (control) and one after irradiation.

\section{Animal model}

Seventy-two adult Wistar rats (weight range from $80 \mathrm{~g}$ to $135 \mathrm{~g}$ ) were used for this experiment. All animals had free access to food and water throughout the study. Before conducting the experiment, rats were acclimatized to the animal house conditions (12:12 h light/ dark cycle) for a week. Standard pellet feed and drinking water were provided.

Rectal temperatures (TR) were recorded by inserting a lubricated digital thermometer (external diameter: $3 \mathrm{~mm}, 0.1^{\circ} \mathrm{C}$ precision) $2.8 \mathrm{~cm}$ into the rectum of rats. Animals presenting initial rectal temperature between $34^{\circ} \mathrm{C}$ and $37^{\circ} \mathrm{C}$ were selected for the tests.

To induce fever of bacterial origin, stock cultures of Klebsiella pneumoniae and P. aeruginosa were sub cultured on MacConkey agar plates and incubated at $37^{\circ} \mathrm{C}$ for $18 \mathrm{~h}$. Bacterial suspensions were prepared by gently removing the growth from MacConkey agar plates and suspending them in nonpyrogenic normal saline. The bacterial density was adjusted to an optical density of 0.6 at wavelength of 600 $\mathrm{nm}$ (approximates $1 \times 10^{9}$ organisms per $\mathrm{ml}$ ) [19]. Each rat was received $1 \mathrm{ml}$ intraperitoneal (i.p.) injection of bacterial suspension. To induce fever of non-bacterial origin, subcutaneous administration of $1 \mathrm{~g} / \mathrm{kg}$ dried baker's yeast (Matroh Co.) as a $20 \%$ suspension in $0.9 \%$ saline solution [20]. Serum IL-6 was assayed using rat IL-6 ELISA (EnzymeLinked Immunosorbent Assay) kit (KOMA BIOTECH ${ }^{\circ}$, Korea) and intensity of colored products was measured spectrophotometrically at $450 \mathrm{~nm}$. The rats were divided randomly into 8 groups, each consisting of 9 animals and treated as described in Table 1.

\section{Statistical analysis}

The significance of differences between groups was calculated with t-test and statistical significance was designated at the $95 \%$ confidence level (two-sided P). The data was analyzed using SPSS version 11.0 for determination of cut-off levels, sensitivity and specificity through ROC (Receiver Operating Characteristic) curves.

\section{Results}

The number and frequency of positive and negative cases for bacterial growth from blood culture samples of feverish cancer patients out of 70 cases revealed that, $34(49 \%)$ positive blood cultures and 36 (51\%) no detected growth. Among the studied cancer patients, there were 38 males beside 32 females with age range from neonates to 72 . The numbers of different bacterial species and their relative percentages isolated from feverish cancer patients (34 cases) represented in Table 2.

The results of C-reactive protein (CRP) measurements revealed that, in cancer patients with gram negative bacteremia $(n=34)$ CRP was ranged from $<3.3 \mathrm{mg} / \mathrm{l}$ (normal levels) to $390 \mathrm{mg} / \mathrm{l}$ and in cancer patients without bacteremia (non-microbial fever) $(n=36)$ it was ranged from $<3.3 \mathrm{mg} / \mathrm{l}$ to $206 \mathrm{mg} / \mathrm{l}$. The data of CRP for both groups were statistically analyzed and revealed that, P-value was non-significant $=0.138$. IL-6 serum concentrations were above normal values during gram negative bacteremia in cancer patients most values were between $136.32 \mathrm{pg} /$ $\mathrm{ml}$ and $2487 \mathrm{pg} / \mathrm{ml}$ with some extreme levels reached $3083.4 \mathrm{pg} / \mathrm{ml}$ with mean value of $2048.9 \mathrm{pg} / \mathrm{ml}$. In the present study, the data of sIL- 6 concentrations showed P-value $=0.0001$ between cancer patients with positive blood cultures and negative blood cultures. For assay of serum levels of IL-8, IL-8 serum concentrations were above normal values in cancer patients with positive blood cultures. In most cases 
Citation: Farrag HA, Aboulwafa MM, Aboshanab KM, Abdelbaset AA (2017) Serum IL-6, IL-8 and CRP as Markers for Prediction of Bacteremia by Gram Negative Rods in Febrile Cancer Patients and in Irradiated Rats. J Med Microb Diagn 6: 258. doi:10.4172/2161-0703.1000258

Page 3 of 6

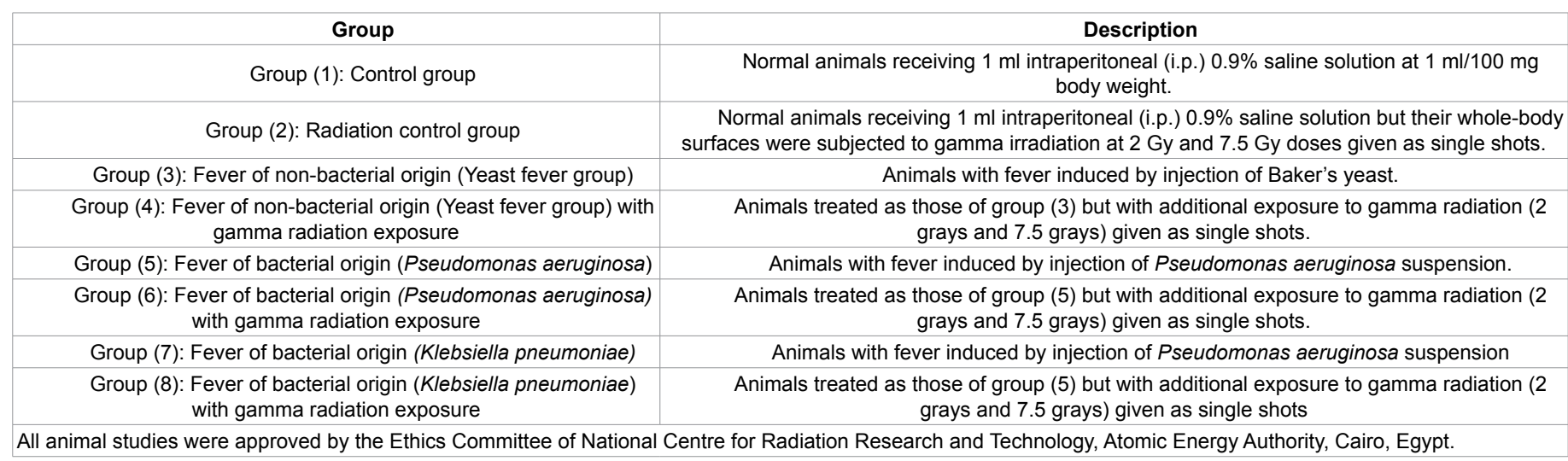

Table 1: Experimental design to study the effect of gamma irradiation on WBCs count and s IL-6 level in animal infection model.

\begin{tabular}{|c|c|c|c|}
\hline Bacterial species & No. of isolates & Frequency $\%$ & *Gender \\
\hline Escherichia coli & 14 & 41 & $7 / 7$ \\
\hline Klebsiellapneumonia & 8 & 23 & $5 / 3$ \\
\hline Pseudomonas fluorescence & 2 & 6 & 2 \\
\hline Pseudomonas putida & 4 & 12 & $2 / 2$ \\
\hline Pseudomonas aeruginosa & 3 & 9 & $2 / 1$ \\
\hline Acinetobacter baumannii & 3 & 9 & $1 / 2$ \\
\hline *Gender: number of males/number of females
\end{tabular}

Table 2: Number and frequency of bacterial species isolated from 70 cancer patients.

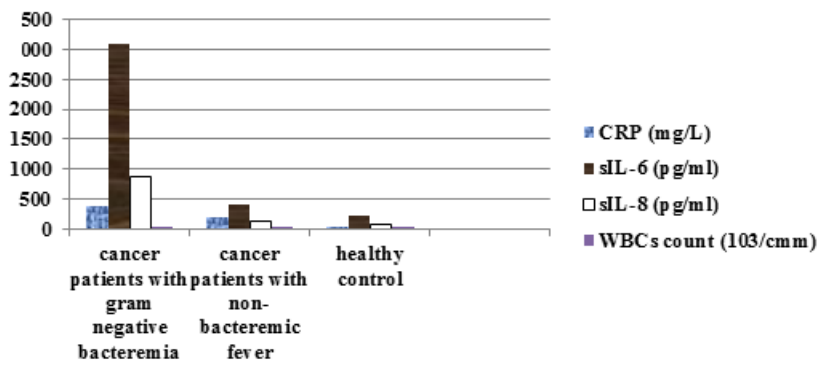

Figure 1: Concentrations of serum CRP, IL-6, IL-8 and WBCs in cancer patients who represented with gram negative bacteraemia, non-bacteraemia fever in comparison to healthy controls.

\begin{tabular}{|c|c|c|c|c|}
\hline Organism (n) & $\begin{array}{l}\text { sCRP } \\
\text { (mg/l) }\end{array}$ & $\begin{array}{c}\text { slL-6 } \\
\text { (pg/ml) }\end{array}$ & $\begin{array}{c}\text { slL-8 (pg/ } \\
\text { ml) }\end{array}$ & $\begin{array}{c}\text { WBCs } \\
\left(10^{3} / \mathrm{cmm}\right)\end{array}$ \\
\hline Escherichia coli (14) & 122.9 & 1413.5 & 343.4 & 1.497 \\
\hline Klebsiella pneumoniae (8) & 242.1 & 1567.4 & 376.05 & 0.4575 \\
\hline Pseudomonas fluorescence (2) & 68.1 & 2466.2 & 691 & 1.88 \\
\hline Pseudomonas putida (4) & 106 & 136.32 & 205 & 0.99 \\
\hline Pseudomonas aeruginosa (3) & 88.2 & 1293.5 & 846.6 & 0.2 \\
\hline Acinetobacter baumannii (3) & 327.5 & 1000.4 & 879.5 & 0.095 \\
\hline
\end{tabular}

Table 3: Mean of Serum levels of CRP, IL-6, IL-8 and WBCs in cancer patients with positive blood cultures.

the values exceeded the normal values recorded with healthy control samples. While, in cancer with negative blood cultures IL-8 serum concentrations recorded dramatically lower values. The results revealed that, P-value $=0.0059$ of IL- 8 serum concentration in cancer patients with positive blood cultures and cancer patients with negative blood cultures (non-microbial fever).

Concentrations of serum CRP, IL-6, IL-8 and WBCs in cancer patients who represented with gram negative bacteremia, nonbacteremic fever in comparison to healthy controls were represented in Figure 1, while mean of serum levels of CRP, IL-6, IL-8 and WBCs in cancer patients with positive blood cultures were listed in Table 3.

C3 serum concentrations were below normal values during bacteremia in cancer patients, most values were between $24.8 \mathrm{mg} / \mathrm{dl}$ and $72.5 \mathrm{mg} / \mathrm{dl}$ with mean value of $40.25 \mathrm{mg} / \mathrm{dl}$. By statistical analysis, it was found that, $\mathrm{P}$-value $=0.3004$ between $\mathrm{C} 3$ serum concentration in cancer patients with positive blood culture and cancer patients with negative blood culture (non-microbial fever). The results reveals that in the positive blood culture, the mean values of different tested serum markers were higher than those with negative blood culture with the most relative increase for IL-6.

For the tested serum markers (CRP, IL-6 and IL-8) it was observed that there was a pronounced difference between the values recorded for IL-8 among positive and negative blood cultures in tested cases. On the other hand, for the other two tested serum markers (CRP and IL-6) the differences in recorded values among positive and negative blood cultures tested cases overlapped in some cases. In such conditions, a statistical test called Receiver Operating Characteristic test (ROC) was applied for discrimination of true positive and true negative values.

Statistical analysis of CRP and IL-6 serum markers of some selected cancer patients with positive blood cultures by Receiver Operating Characteristic Curves (ROC)

The test was performed between positive blood cultures cases and cases with negative blood cultures among cancer patients and represented in Figure 2 revealing cut-off value of CRP $29 \mathrm{mg} / \mathrm{l}$ with Sp $60 \%$, Sn $77.8 \%$, PPV 77.8, NPV 60\% with AUC 0.844 and for sIL-6 the cut-off value was $398.6 \mathrm{pg} / \mathrm{ml}$ and Sp 60\%, Sn 77.8\%, PPV 77.8, NPV 60\%, AUC 1.00 Table 4.

\section{Effect of gamma irradiation on IL-6 serum levels in rats with induced fever of bacterial and non-bacterial origin}

It was clear that IL-6 serum level ranged from $873.4 \mathrm{pg} / \mathrm{ml}$ to 1104 $\mathrm{pg} / \mathrm{ml}$ in normal rats received saline only. However, the effect of gamma irradiation exposure caused an increase in rat serum levels of IL-6 reaching $1197 \mathrm{pg} / \mathrm{ml}$ and $1245 \mathrm{pg} / \mathrm{ml}$ at radiation doses of 2 grays and 7.5 grays. In yeast fever group representing fever of non-bacterial origin, rat IL-6 serum levels ranged from $965 \mathrm{pg} / \mathrm{ml}$ to $1426.6 \mathrm{pg} / \mathrm{ml}$, while when rats were exposed to radiation, their IL- 6 serum levels elevated to $1470 \mathrm{pg} / \mathrm{ml}$. In bacteremia fever groups, there were very high elevations in rat IL-6 serum levels reaching $27284 \mathrm{pg} / \mathrm{ml}$ and with exposure to gamma radiation the IL-6 serum levels reached $29753.9 \mathrm{pg} / \mathrm{ml}$. WBCs count decreased in gamma irradiated rats and in irradiated rats pretreated with yeast. While, in bacteremia fever groups with exposure 


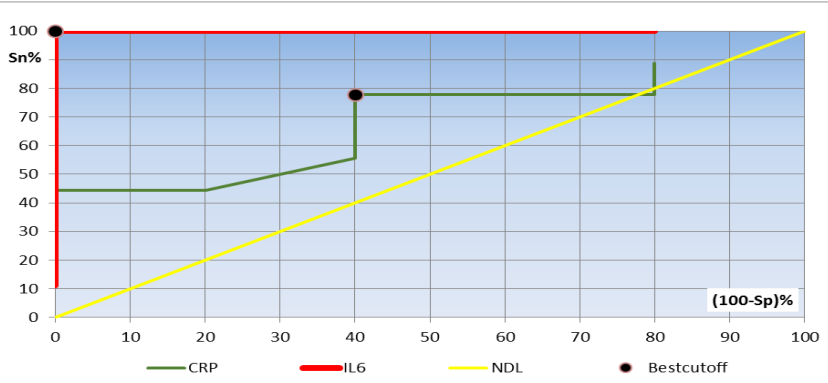

Figure 2: ROC curve showing the diagnostic performance of serum CRP and IL-6 for discriminating cancer patients with positive blood cultures from those with negative blood cultures.

\begin{tabular}{|c|c|c|c|}
\hline Infection status & CRP (mg/l) & IL-6 $\mathbf{( p g / m l )}$ & IL-8 (pg/ml) \\
\hline Bacterial infection n=34 & 120.2 & 2048.9 & 585.43 \\
\hline No bacterial infection n=36 & 69.3 & 228.89 & 101.9 \\
\hline $\begin{array}{c}\text { Ratio of bacterial infection/no } \\
\text { bacterial infection }\end{array}$ & 1.73 & 8.95 & 5.7 \\
\hline $\begin{array}{c}\text { P. value between bacterial infection } \\
\text { and no bacterial infection }\end{array}$ & 0.138 & 0.0001 & 0.0059 \\
\hline
\end{tabular}

Table 4: Mean values of tested serum markers (CRP, IL-6 and IL-8) in feverish cancer patients.

\begin{tabular}{|l|c|c|c|}
\hline \multirow{2}{*}{ Group no. } & \multicolumn{3}{|c|}{ Parameters } \\
\cline { 2 - 4 } & Rectal Temp. (TR) & WBCs ( (10 $\left.^{\mathbf{9}} \mathbf{L}\right)$ /Average & slL-6 (pg/ml)/Average \\
\hline Group (1) & $34-36.3$ & $3-9.4 / 7.4$ & $873.4-1011.6 / 996$ \\
\hline Group (2) & $34-36$ & $3.9-5.3 / 4.8$ & $1059-1245 / 1127.9$ \\
\hline Group (3) & $36.6-38.3$ & $2.5-9.4 / 5.6$ & $965-1426.6 / 1180.6$ \\
\hline Group (4) & $34.9-37.4$ & $2.6-5.6 / 4.3$ & $1102-1470 / 1295.5$ \\
\hline Group (5) & $34.7-36.9$ & $2.1-5.3 / 3.5$ & $23736-$ \\
\hline Group (6) & $34.4-37.3$ & $5.1-11 / 7.85$ & $25806-28208 / 26952.3$ \\
\hline Group (7) & $32.1-36.9$ & $1.4-4.8 / 3.1$ & $1472.6-27284 / 20814.8$ \\
\hline Group (8) & $33.9-37.3$ & $1.1-6.5 / 2.9$ & $19262-$ \\
\hline
\end{tabular}

Table 5: Rectal temperature, white blood cells count and IL-6 serum concentration in different groups of rats.

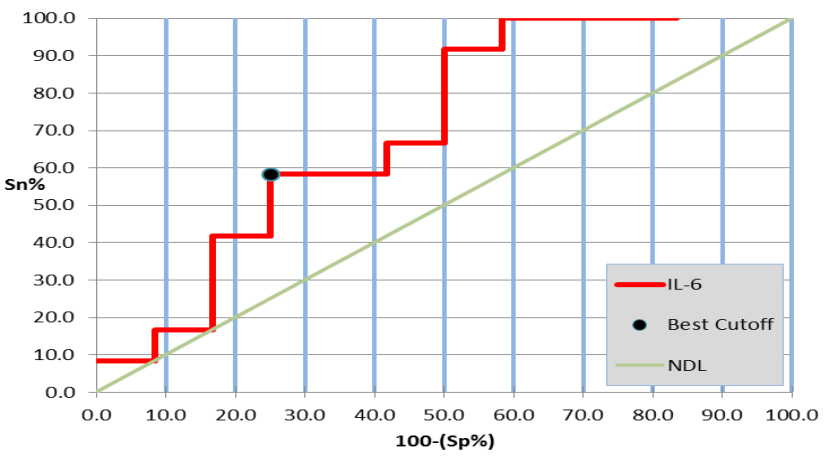

Figure 3: ROC curve analysis showing the diagnostic performance of serum IL-6 for discriminating rats with bacteraemia (bacteraemia fever) with exposure to gamma radiation from those with bacteraemia fever without exposure to gamma radiation.

to gamma irradiation WBCs count was higher than that measured in bacteremia fever groups without gamma irradiation exposure.

For the different treated rat groups as well as control groups, the rectal temperature, white blood cells count and IL-6 serum concentrations determined at the end of the experiment from blood samples of sacrificed animals and the results are represented in Table 5.

\section{Statistical analysis of IL-6 serum levels in bacteremic groups with and without exposure to gamma irradiation by Receiver Operating Characteristic Curve (ROC)}

Diagnostic validity test Receiver Operating Characteristic Curve (ROC) was done between bacteremia groups (due to P. aeruginosa and Klebsiella pneumoniae) with exposure to gamma irradiation (groups 6 and 8 ) and bacteremia groups without exposure to gamma radiation (groups 5 and 7) for IL-6 serum concentration as represented in Figure 3, showing cut-off value of $25740 \mathrm{pg} / \mathrm{ml}$ with $75 \%$ specificity, $58.3 \%$ sensitivity, negative predictive value 64.3 and positive predictive value 70 .

\section{Discussion}

In this study, the prevalence of gram negative bacteremia among 70 feverish cancer patients was $49 \%$ and the most frequently isolated gram-negative rods were E. coli (41\%) followed by Klebsiella pneumoniae (23\%) then Pseudomonassp. (27\%). Reyes et al. [21] reported that prevalence of bacteremia for all cancer, neutropenia and fever events was $24.3 \%$ and gram-negative bacteria were predominant $(65 \%)$, the ratio of isolates of gram negative and gram positive was 2.2. The most frequently isolated bacteria were Pseudomonas sp. (21.6\%).

Many studies associate bloodstream infections in cancer patients with gram-negative bacteria. Amongst gram-negative rods, E. coli was the most common isolate; in cancer patients, twice as many BSIs were caused by P. aeruginosa and Enterobacter cloacae [22]. LPS in gram-negative bacteria leads to increases in expression of IL-6 and IL-8 $[23,24]$. Granzymes are serine proteases released by cytotoxic lymphocytes and induce cell death in virus-infected cells and tumor cells. However, granzymes also exist extracellularly in the blood circulation of patients with autoimmune diseases and infections and may contribute to inflammation. Human granzyme (GrK) binds to gram-negative bacteria and to lipopolysaccharide (LPS), a gram negative bacterial cell wall component. The data indicated that GrK lowers the threshold for monocyte activation by LPS, in that GrK synergistically increases LPS-induced release of proinflammatory cytokines in-vitro and in-vivo. In conclusion, GrK modulates the innate immune response against LPS and Gram-negative bacteria and may contribute to the pathogenesis of diseases associated with a local or systemic bacterial infection [25]. A valuable marker of infection with gram-negative rods in this setting would be associated with high sensitivity and specificity for predicting infection. CRP serum concentrations in our study showed nonsignificant difference between bacteremia group and group of nonmicrobial fever (P-value $=0.138)$ with NPV of $60 \%$ and PPV of $77.8 \%$ (Sn.77.8 and Sp. 60). Currently used conventional infection markers such as CRP level, WBC count and the erythrocyte sedimentation rate have relatively poor discriminatory capacity in distinguishing patients with bacterial infections versus patients with nonbacterial infections [26]. Though CRP is the most commonly measured acute parameter in infection and sepsis, it is not a reliable marker in identifying bacterial infection because of its low sensitivity and specificity [27]. In the present study, there was significant difference in IL-6 serum concentration in cancer patients with positive blood cultures and negative blood cultures $(\mathrm{P}$-value $=0.0001)$. Our results found that IL- 6 was discriminatory marker between bacteremia and non-bacteremia fever in cancer patients with high NPV of $100 \%$ and PPV of $100 \%$. Levels of IL- 6 in serum were measured because this cytokine is thought to have a central signaling function in the inflammatory response to microbial infection, i.e., induction 
Citation: Farrag HA, Aboulwafa MM, Aboshanab KM, Abdelbaset AA (2017) Serum IL-6, IL-8 and CRP as Markers for Prediction of Bacteremia by Gram Negative Rods in Febrile Cancer Patients and in Irradiated Rats. J Med Microb Diagn 6: 258. doi:10.4172/2161-0703.1000258

of acute phase reaction by Johan et al. in 2001. A previous study showed IL- 6 as a better prognostic marker of bacterial infection than CRP in patients with febrile neutropenia by Von LilienfeldToal et al. in 2004. the highest serum concentrations of IL-6 were observed in episodes of gram-negative bacteremia in cancer patients and gram-positive organisms but higher in former [28].

The data of sIL-8 in our study revealed that, there was significant difference in IL- 8 serum concentration in cancer patients with positive blood cultures and cancer patients with negative blood cultures (non-microbial fever) P-value $=0.0059$. When measuring IL-8 serum concentrations, there were strict differences in concentrations between bacteremia and non-bacteremia fever groups reaching $100 \%$ specificity and sensitivity. Al-Jebouri and Hasen, [28] found in their study, that IL-8 levels were elevated earlier and higher in leukemic patients with gram negative sepsis by E. coli or Klebsiella pneumoniae and they also found that levels were likewise elevated in gram-positive sepsis, but less-so than with gram-negative infection. Release of IL-8 in Human whole blood cells were challenged with LPS at time zero, and IL-8 protein levels were determined at 0.5 hour, 1 hour, and 3 hours. All of these antigens significantly $(P<0.05)$ induced IL- 8 production at 1 hour after exposure and continued to do so at 3 hours [13].

Serum levels of complement C3 were decreased in bacteremia patients meaning there was activation of the complement system by gram negative bacteremia with non-significant difference (P-value $=0.3004)$ between the studied groups. The peak C3a did not contribute to prediction of a positive culture by Von Lilienfeld-Toil et al. in 2004. Ongoing activation of the complement pathway may be a risk factor for poor prognosis, and persistently depressed serum complement protein levels may be an indirect marker for this [29].

In the present study, for cancer patients with gram negative bacteremia, there were significant relationships between $P$-value $=0.0114$. Also, there was significant correlation between IL-8 and IL-6 serum levels with $\mathrm{P}$-value $=0.0026$. Meanwhile, there was non-significant relationship between IL- 8 and WBCs with P-value $=0.18$ and significant relationship between IL-6 serum levels and WBCs count with P-value $=0.000025$. A relation between serum concentrations of IL- 6 and CRP was described for cancer patients with Gram- negative bacteremia showing $\mathrm{P}$-value $=0.006$. Meaning that IL- 6 playing role in chemotaxis of white blood cells to site of infection cancer patients, A plausible explanation for the higher levels of IL- 6 in patients with neutropenia may be related to the fact that gram-negative bacteria release high concentrations of endotoxin, which directly activates monocytes via the CD14 receptor [30]. When kinetics of IL-8, IL-6, CRP and WBCs Count were studied, no significant correlation was seen between IL-8 concentrations and numbers of WBCs. However, IL-8 correlated positively with circulating CRP and IL-6 in patients with sepsis syndrome [31,32]. The lowest median value for serum IL- 8 was found in patients with unexplained fever, high IL-8 levels were correlated with gram-negative bacteremia, based on the above findings it appears that serum IL- 8 measurement may be valuable to predict early complicated courses of bacteremia infection in the neutropenic host [11]. In comparison to CRP, the IL-8 level seems to be more worthwhile for discriminating infectious from non-infectious causes in neutropenic febrile patients, especially at the start of febrile episode [33]. Concern regarding radiation effects on human health continues to increase worldwide, given that infection is a major cause of morbidity and mortality after exposure. Gray (Gy) is the unit used to measure the total about of radiation the patient is exposed to. This can also be recorded as centigray (cGy), which is 0.01 of a single gray unit. Adjuvant therapy doses typically range from $45 \mathrm{~Gy}$ to $60 \mathrm{~Gy}$ for cancer of the breast, head and neck, which is divided into multiple smaller doses given over a period of one to two months. In our study, we applied low dose radiation as 2 Gray (mean dose of two days fractionation administered to cancer patients given as one-shot dose) and high dose radiation represented as 7.5 Gray (mean dose of five days fractionation administered to cancer patients given as one-shot dose). Sarkar et al declared that $8 \mathrm{~Gy}$ is considered a lethal dose for rats.

Michael et al. in 2014 [34] recorded that when mice were exposed to total-body irradiation (TBI) with $3 \mathrm{~Gy}$ protons (70 cGy/min). One day, 2 days, 4 days, 8 days or 16 days later, subsets of mice were injected intraperitoneally with live E. coli, the results showed that there were no unexpected effects of radiation or E. coli alone. Despite dramatic radiation-induced decreases in all leukocyte populations in both the blood and spleen, irradiated mice were still able to respond to an immune challenge based on capacity to generate an oxidative burst and secrete inflammatory cytokines, i.e., tumor necrosis factor- $\alpha$ (TNF- $\alpha$ ) and IL-6. However, these responses were generally elevated above control values. These cytokines (IL- 6 and TNF- $\alpha$ ) are rapidly synthesized and secreted by inflammatory cells upon stimulation and in turn induce the production of adhesion molecules and other inflammatory mediators [35].

In gamma irradiation exposure groups (a) bacteremia fever (Pseudomonas aeruginosa and Klebsiella pneumoniae with exposure to gamma radiation (group 6,8) and (b) non-bacteremia fever (Radiation exposure+yeast) (group 4), it was observed that there was significant difference in IL-6 serum concentration in bacteremia fever group exposed to gamma radiation and non-bacteremic fever group exposed to gamma radiation P-value $=0.0001$ (for $P$. aeruginosa group) and 5.9 $\times 10^{-8}$ (for Klebsiella pneumoniae group). While, in groups that were not exposed to gamma radiation (a) bacteremic fever ( $P$. aeruginosa and Klebsiella pneumoniae) (group 5,7) and (b) non-bacteremia fever (yeast fever) (group 3), there was significant difference in IL-6 serum concentrations between group of bacteremic fever due to $P$. aeruginosa and non-bacteremia fever group due to yeast with $P$-value $=0.0001$ and between group of bacteremia fever due to Klebsiella pneumoniae and non-bacteremia fever group due to yeast with $\mathrm{P}$-value $=0.000657$. For $P$. aeruginosa bacteremia group with exposure to gamma radiation (group 6) and bacteremia group without exposure to gamma radiation (group 5) there was significant difference in serum IL-6 concentration P-value $=0.0412$ and for Klebsiella pneumonia bacteremia group (group 8 ) with exposure to gamma radiation and bacteremia group without exposure to gamma radiation (group 7) there was non-significant difference in serum IL- 6 concentration Ps-value $=0.27$. In studying the effect of gamma radiation exposure, IL- 6 serum concentration in group exposed to gamma radiation was significantly different from bacteremia group and bacteremia group with exposure to gamma radiation. P-value $=0.0001$ between gamma radiation exposure group (group 2) and bacteremia group due to P. aeruginosa (group 5) while, for Klebsiella pneumoniae group (group 7) P-value $=0.0006518$. Also, there was significant difference in IL- 6 serum concentration between gamma radiation exposure group (group 2) and bacteremia group due to $P$. aeruginosa and Klebsiella pneumoniae with exposure to gamma radiation (groups 6 and 8 ) $\mathrm{P}$-value $=0.0001$ and $5.5 \times 10^{-8}$, respectively. For yeast group (non-bacteremia fever without exposure to gamma radiation) (group 3) and non-bacteremia fever with exposure to gamma radiation (group 4) there was non-significant difference in IL-6 serum concentration P-value $=0.2726$. From the results of ROC, we concluded that serum IL- 6 concentration can be used as good marker for differentiation between bacteremia fever and non-bacteremia fever also radiation exposed groups. 
Citation: Farrag HA, Aboulwafa MM, Aboshanab KM, Abdelbaset AA (2017) Serum IL-6, IL-8 and CRP as Markers for Prediction of Bacteremia by Gram Negative Rods in Febrile Cancer Patients and in Irradiated Rats. J Med Microb Diagn 6: 258. doi:10.4172/2161-0703.1000258

Page 6 of 6

\section{Conclusion}

In conclusion, IL-6 and IL-8 may be valuable biomarkers of gramnegative bacteremia in febrile cancer patients under radiotherapy and/ or chemotherapy with greater predictive value than CRP. C3 may not be a valuable marker of identifying bacterial infection.

\section{References}

1. Hugonnet S, Sax H, Eggimann P, Chevrolet JC, Pittet D (2004) Nosocomial bloodstream infection and clinical sepsis. Emerg Infect Dis 10: 75-81.

2. Young LS (2008) Bacteremia. Merck Manual Home Health Handbook. Accessed on 29 July 2017.

3. Diepold M, Noellke P, Duffner U, Kontnyand U, Berner R (2008) Performance of Interleukin-6 and Interleukin-8 serum levels in pediatric oncology patients with neutropenia and fever for the assessment of low-risk. BMC Infect Dis 8: 28.

4. Marnell L, Mold C, Du Clos TW (2005) C-1. reactive protein: Ligands, receptors and role in inflammation. Clin Immunol 7: 104-111.

5. Mitaka C (2005) Clinical laboratory differentiation of infectious versus noninfectious systemic inflammatory response syndrome. Clin Chim Acta 351: 17-29.

6. Reimer LG, Wilson ML, Weinstein MP (1997) Update on detection of bacteremia and fungemia. Clin Microbiol Rev 10: 444-465.

7. Smith M (2010) MedPageToday. N Engl J Med.

8. Aalto $H$, Takala A, Kautiainen H, Repo $H$ (2004) Laboratory markers of systemic inflammation as predictors of bloodstream infection in acutely ill patients admitted to hospital in medical emergency. Eur J ClinMicrobiol Infect Dis 23: 699-704.

9. Gaïni S, Koldkjær OG, Pedersen C, Pedersen SS (2006) Procalcitonin lipopolysaccharide-binding protein, interleukin-6 and C-reactive protein in community-acquired infections and sepsis: A prospective study. Crit Care 10: R53.

10. Kellum JA, Kong L, Fink MP, Weissfeld LA, Yealy DM, et al. (2007) Understanding the inflammatory cytokine response in pneumonia and sepsis. Arch Intern Med 167: 1655-1663.

11. Engel A, Knoll P, Kern P, Kern WV (2005) Interleukin-8 serum levels at fever onset in patients with neutropenia predict early medical complications. Infection 33: $380-382$.

12. Petersen SV, Thiel S, Jensenius JC (2001) The mannan-binding lectin pathway of complement activation: biology and disease association. Mol Immunol 38: 133-149.

13. Reid KBM, Colomb MG, Petry F, Loos M (2002) Complement component C1 and the collectins-first line defense molecules in innate and acquired immunity. Trends Immunol 23: 115.

14. Panghal M, Kaushal V, Kadayan S, Yadav JP (2012) Incidence and risk factors for infection in oral cancer patients undergoing different treatments protocols. BMC Oral Health 12: 22.

15. Paterson DL, Rice LB (2003) Empirical antibiotic choice for the seriously ill patient: Are minimization of selection of resistant organisms and maximization of individual outcome mutually exclusive? Clin Infect Dis 36: 1006-10012.

16. Peleg AY, Hooper DC (2010) Hospital-acquired infections due to gram-negative bacteria. N Engl J Med 362: 1804-1813.

17. Peters RP, Van Agtmael MA, Danner SA (2004) New developments in the diagnosis of bloodstream infections. Lancet Infect Dis 4: 751-760.

18. Burton GRW (1995) Microbiology for the health sciences. (4th edn), Chapter 6 Human and microbial infection. JB Lippincott Company, Philadelphia, New York, Hagerston.

19. Zager RA, Prior RB (1986) Gentamicin and gram-negative bacteremia. A synergism for the development of experimental nephrotoxic acute renal failure. J Clin Invest 78: 196-204

20. Engelhardt G, Homma D, Schlegel K, Utzmann R, Schnitzler C (1995) Antiinflammatory, analgesic, antipyretic and related properties of meloxicam, new non-steroidal anti-inflammatory agent with favourable gastrointestinal tolerance. Inflamm Res 44: 423-433.

21. Reyes JC, Aguilera MM, Zamora AC, Meza JG (2013) Frequency of risk factors for bacteremia in children with cancer, neutropenia and fever in a tertiary level hospital in western Mexico. Bol Med Innfant Mex 70: 303-308.

22. Bos MM, Smeets LS, Dumay I, De Jonge E (2013) Bloodstream infections in patients with or without cancer in a large community hospital. Infection 41: 949 958.

23. Sawa Y, Ueki T, Hata M, Iwasawa K, Tsuruga E, et al. (2008) LPS-induced IL6, IL-8, VCAM-1, and ICAM-1 expression in human lymphatic endothelium. J Histochem Cytochem 56: 97-109.

24. Smith JA (1994) Neutrophils, host defence, and inflammation: A double-edged sword. J Leukoc Biol 56: 672-686.

25. Wensink AC, Kemp V, Fermie J, Laorden MIJ, Van Der Poll D, et al. (2014) Granzyme K synergistically potentiates LPS-induced cytokine responses in human monocytes. PNAS 111: 5974-5979.

26. De Jager CPC, Van Wijk PTL, Mathoera RB, De Jongh-Leuvenink J, Van Der Poll T, et al. (2010) Lymphocytopenia and neutrophil-lymphocyte count ratio predict bacteremia better than conventional infection markers in an emergency care unit. Crit Care 14: R192.

27. Junyan QU, Xiaoju Lü, Xiaohui W (2015) Evaluation of procalcitonin, C-reactive protein, interleukin- 6 and serum amyloid: A diagnostic biomarker of bacterial infection in febrile patients. Indian J Med Res 141: 315-322.

28. Al-Jebouri MM, Hasen AM (2015) New biomarkers as indicators for sepsis in febrile leukemic Iraqi patients. WJPR 4: 489-496.

29. Sungurtekin $H$, Sungurtekin U, Balci $C$ (2006) Circulating complement (C3 and C4) for differentiation of SIRS from sepsis. Adv Ther 23: 893-901.

30. Lehrnbecher T, Venzon D, De Haas M, Chanock SJ, Kuhl J (1999) Assessment of measuring circulating levels of interleukin-6, interleukin-8, C-reactive protein soluble $\mathrm{Fcg}$ receptor type III, and mannose-binding protein in febrile children with cancer and neutropenia. Clin Infect Dis 29: 414-419.

31. Lindemann A, Tamm I, Tanodi K, Mertelsmann R (1995) Interleukin-8 serum levels for early detection of infectious episodes in neutropenic patients. $J$ Infect Dis 172: 610.

32. Hirao Y, Kanda T, Aso Y, Mitsuhashi M, Kobayashi I (2000) Laboratory Medicine 31: 39-44.

33. Tromp YH, Daenen SM, Sluiter WJ, Vellenga E (2009) The predictive value of interleukin-8 (IL-8) in hospitalized patients with fever and chemotherapyinduced neutropenia. Eur J Cancer Care (Engl) 45: 596-600.

34. Pecaut MJ, Baqai FP, Gridley DS (2014) Impact of total-body irradiation on the response to a live bacterial challenge. Int J Radiat Biol 90: 515-526.

35. Moriconi F, Malik I, Ahmad G, Dudas J, Rave-Frank M, et al. (2009) Effect of irradiation on gene expression of rat liver adhesion molecules: In vivo and in vitro studies. Strahlenther Onkol 185: 460-468. 